\title{
A Literature Review on Caffeine Related Disorder in Line with Coffee Addiction
}

\author{
Patrizia Muradi ${ }^{* 1}$ and Aylin Tutgun Ünal ${ }^{2}$ \\ ${ }^{1}$ Department of Psychology, Üskudar University, İstanbul/Turkey \\ ${ }^{2}$ Assoc. Prof. Faculty of Communication, Üsküdar University, \\ İstanbul, Turkey
}

\author{
${ }^{*}$ Corresponding author \\ Patrizia Muradi, Department of Psychology, Üskudar University, İstanbul/ \\ Turkey.
}

Submitted: 14 Jan 2022; Accepted: 18 Jan 2022; Published: 24 Jan 2022

citation: Patrizia Muradi and Aylin Tutgun Unal (2022) A Literature Review on Caffeine Related Disorder in Line with Coffee Addiction J Addict Res 6(1): 151-155.

\begin{abstract}
Summary
Coffee is a widely popular and beverage in our day. It is widely consumed in many societies and the amount of this consumption has been gradually increasing over the years. However, because of the caffeine and some other chemical substances that it contains, it can give rise to addiction cases when used in excessive amounts; and, the American Psychiatric Association's having given place to warnings that it might cause withdrawal and intoxication, in its DSM V published in 2013, it directed the attention of the science world to this aspect and gave a wing to the studies. In this study, especially worldwide international publications released in recent years have been examined, aiming to handle the benefits and damages of coffee consumption in line with caffeine addiction. In this sense, the literature has been synthesised using the document review method, offering guiding information for future studies about the relation between coffee addiction and caffeine consumption disorder. In addition to recommended doses and overdose amounts, an important warning made by the experts is that the consumption criteria is different for each individual. However, it is considered important to take into account the possible effects of overdose consumption especially on pregnant women and children.
\end{abstract}

Keywords: Coffee, Coffee Addiction, Caffeine Addiction, Caffeine

\section{Introduction}

Having a history enriched with various stories, "Coffee" is one of the considerably widely consumed beverages served through various preparation methods. This beverage that has an extensive role in many cultures, emerged in the Arab Peninsula in the 15th century and was introduced to the Ottoman Empire, which became popular among both the royal family and the public. The coffee sacks left by the Ottoman Army after the Siege of Vienna led to the spread of this product in Europe [1]. The study published by Robert Burton in 1632, titled "The Anatomy of Melancholy" defines Coffee as a Turkish beverage and mentions that people of that region in that century used to gather at Coffee Houses and consume tea and coffee [2]. It is a widely well known fact that beverages that seem ordinary like Cacao and Cola consist in the Caffeine substance as does Coffee.

Considered by many people as a beverage that helps start the day in the morning and enhances the working performance during the day, coffee has created an industry itself with its smell, taste, look and various presentations in recent years. Another point that should be considered on the other hand is the scientific studies proposing that the Caffeine substance contained in coffee might cause consumption disorders. It is also necessary to take into account that caffeine is a stimulant that affects the central nervous system, leads to changes in metabolism and psychological mood, and thus may cause loss of appetite and insomnia [3]. This study mainly focuses on the views about whether caffeine causes addiction or not through inclusion of studies on its possible benefits and harms.

\section{Method}

In this study, the document review method has been used and studies related with caffeine have been interpreted in the sense of benefits, harms and addiction. Related books and articles available on Google and online libraries have been examined. As is known, document review means the analysis of written materials that include information on the research subject [4]. The purpose of the study is to remind once again what is known as well as to share the actual data available in the international literature in recent years. As the obtained resources are examined, caffeine consumption disorder is categorized under the titles of the relation between coffee and caffeine, caffeine withdrawal and its negative effects. An actual literature synthesis is presented by including some of the reports and scientific facts published on the internet. 


\section{Caffeine Consumption Disorder}

It is a known fact that caffeinated drinks like coffee and tea may cause behavioral changes due to the substance they contain [5]. In the final version of DSM V used for diagnosing psychological problems published in 2013, The American Psychiatric Association records it under the roof of "Substance related disorders and addiction disorders), underlining that it causes substance extacy (intoxication) and withdrawal. As for the amount of use of substance, it defines consumptions over $250 \mathrm{mg}$ as high dosis. The third section in the DSM V highlights the caffeine consumption disorder and criteria in the part explaining some issues that require measures to be taken.

Generally, addiction is a subject that people avoid to mention. As it is developed slowly in some cases, it is possible that the addiction has reached an irreversible stage when realized by the individual himself or by the people around. As we consider that the addiction status consists of three or more symptoms that accompany substance consumption in 12 months, it is understood that continuous consumption of caffeine may cause problems [6]. On the other hand, as mentioned in the DSM V, labeling something as a disorder requires a satisfactory amount of studies to be carried out on the subject. In this sense, researchers draw attention primarily to the amount consumed as they do not comment much on limited consumptions while they warn that overdose usage may cause addiction.

It is observed that the symptoms of caffeine withdrawal in cases of caffeine consumption disorder that might develop according to individuals' anatomical structures, past lives, family doctrines and the situation of the society that they live in, generally match the status indicated on addiction charts. According to DSM V, these symptoms are; headache, obvious status of fatigue or apathy, an emotional state accompanied by Dysphoria, easily getting upset with something or someone, having difficulties about focusing on a certain subject are among the initial symptoms of withdrawal. Finally, the DSM V states that in withdrawal status, flu-like symptoms may be observed, which appear as nausea, vomiting, muscle pain and hardening [7].

\section{The Relation Between Coffee and Caffeine}

The fact that consuming anything at considerable amounts is enough while too much of anything is bad is a frequently testable matter in he daily life, which is important to consider for a healthy living. Although the amount of consumption depends on the individual's decision, it is essential to know the benefits and harms in the first place and consider the situation accordingly. While caffeine is contained in various substances, the scannings show that the studies are mainly carried out around coffee. The facts that in the ICD-10 released by the World Health Organization (WHO) considered coffee among substances that might cause mental and behavioral disorders, that it focused on the studies carried out afterwards that the ICD 11 first listed it among addictive substances but removed it from the list in the following edition, show that the experts actually are not comfortable with this issue and that they have difficulty in categorizing the caffeine substance $[8,9]$.

The caffeine, or "trimethylxanthine" as known in the science world, is a stimulant that's mainly contained in coffee, tea, products made of chocolate and beverages like cola. While it helps the brain keep awake due to its stimulating effect, it increases the release of adrenalin in the body, activates the dopamine reserves and thus stimulates the brain's pleasure center and creates a positive psychological state. Coffee distinguishes among others for the amount of caffeine that it contains. Because $150 \mathrm{ml}$ of coffee contains around 60-150 miligrams of caffeine. Some of the counted benefits are that it helps lose weight, enhances performance in sports, keeps the attention awake, has an antioxidant nature for the polyphenol contained, and that it might have positive effects on memory problems and cancer diseases [10]. Its supportive effect on the treatment of obesity is among the findings of some studies held [11]. In addition to situations like insomnia, dehydration in the body, hypertension, anger, shivering, anxiety, it is among the harming elements that's considered to have a risk of interaction with some medicines [12]. In a follow-up research held between the years 1995 and 2008, which studied the coffee-related death ratios, it was determined that even when the existence of damages of alcohol, smoking, etc. were ignored, there was a considerable relation between coffee and death ratios [13].

Staying away from the caffeine substance after constant use can cause such syndromes like headache, tiredness, stupefaction, etc [14]. Although this easily obtainable substance, consumption of which does not lead to any social problems had been banned at certain times in the history, it is consumed by the children, who are known to have a higher sensitivity due to their small bodies through some beverages that contain caffeine $[15,16]$. This situation leads to the idea that it might be an appropriate decision to limit coffee consumption for children or even to keep them away until they reach a certain age. When we consider that it has been consumed without any restriction for centuries, we develop the idea that this substance provided through caffeinated drinks that are mainly categorized as beverages has not attracted proper attention until now. On the other hand, it has recently begun to be considered that this substance may cause some potential psychological and physiological problems in young people that meet with chocolate, tea, coffee, etc. at early ages, due to its stimulant nature as well as the risk that it might lead to consumption disorder [17]. It is also among the findings of studies that caffeine consumption leads to changes in the body's blood pressure [18]. When it is considered that blood pressure is an important issue especially for patients with high blood pressure, their doctors' advice to stay away from coffee is understandable.

The studies show that overconsumption is common especially among students. It is observed that caffeine consumption is pretty common among students that consume it mainly in forms like coffee, tea, energy drinks, cola, etc. for it keeps them awake. How- 
ever, the negative effects of caffeine on health should be taken into account and its consumption should be taken under control [19]. It seems to be inevitable that caffeinated drinks will remain among popular beverages during exam periods as it is a widely accepted idea that it helps to "avoid sleeping" or "increase concentration" despite the warnings and clinically important studies. Although the idea that it helps individuals focus on their studies for long hours, the risk of developing a consumption disorder through excessive use is an important point to consider. While some of the data obtained show that some consumers may develop a clinically considerable addiction, for now there isn't any satisfactory study on how to cure or prevent that disorder [20]. Although the studies held do not offer any certain treatment, they show that the concerns on this matter actually started a long time ago, however, as it was considered as a behavioral problem, they intended to find a remedy accordingly [21]. In our day, the experts study on some programs focused on Cognitive Therapy to find a solution against overconsumption [22].

\section{Caffeine Withdrawal and its Negative Effects}

Many experts that study addiction agree on the existence of a concept named caffeine withdrawal and an important majority considers that this is a situation that should be examined clinically [23]. Among its important effects, we can count that; its overconsumption might be closely associated with emerged mental health issues that it may support addiction while leading to stress, anxiety, burnout syndromes that it has an effect to increase the heart rate while reducing the need for sleeping [24-26]. The fact that stress, anxiety and burnout syndromes, which are considered among important diseases of our time and are intended to be treated through medicine and therapeutic methods, may be emerging as a result of excessive caffeine consumption is another situation that should receive considerable attention.

While the dose contained in the products available in the market may not pose any risk, especially the energy drinks that can be consumed with alcoholic drinks can increase the harm of caffeine. At this point, it should be considered that pregnant women, children or individuals with mental diseases may be affected by external factors more than usual [27]. Because coffee is a combination of active chemicals that contain caffeine in addition to phenolic polymers, chlorogenic acid [28]. Another important issue is that although it is possible to consider that each product available in the market contains a fair amount of caffeine, it is not possible, at least in our day, to supervise the number of products sold to children. For this reason, the inability to detect the amount of such products when consumed especially by the children through foods and drinks, emerging of situations that form the basis for consumption disorders is possible. In this sense, families or caregivers have important responsibilities.

There are available studies on coffee consumption among children at ages nine to ten and its conclusions. The results show that, even if some conditions like socioeconomic status, gender, sleeping are considered even, there's an avoidant relationship between coffee consumption and vocabulary, understanding, memory processing speed and episodic memory [29]. Thus, this inevitably brings to mind the question whether the memories of minors' at developmental ages who started at early periods and still continue to consume caffeinated drinks, will be affected, too.

While its consumption as of the adolescence period has a predictor effect on aggressive behaviours, it can be mentioned that it helps the adolescent improve their focus depending on the amount consumed, similarly as in adults [30-32]. It is also among the findings that it affects some symptoms like headache, anger, insomnia for it stimulates the important parts of the nervous system [33]. Another important information is that; although there is a positive and strong correlation between caffeine and smoking, unfortunately the underlying reasons could not be defined yet [34]. Regardless of the fact that the underlying reasons are not defined, it can be observed that coffee and cigarettes are generally consumed together in daily life, especially in social environments.

For sure, not all the studies focus solely on results of caffeine that might be risky. While some of the studies suggest that it is not necessary to consider it under the title of addiction, some researches focus on its positive sides. Among its most important characteristics, we can count that it prevents the condition of stupefaction by blocking the performance of adenosine that causes apathy; that it has a better natured physiological profile when compared to other stimulants; that it stimulates dopamine when consumed at high doses [35]. In some of the epidemiological studies held, it was observed that this substance might be a measure against Parkinon's it might reduce the endometrial (uterine cancer) risk, and that its consumption in tea form reduces the risk of cancer in general [36]. Some epidemiological studies and experimental researches state that coffee consumption may have positive effects on type 2 diabetes and liver diseases, the increasing cohort studies have not achieved any result that associates cardiovascular diseases with coffee consumption [37]. While it is stated that non-excessive consumption of coffee might have positive effects on health, there are also warnings that pregnant women should be considered out of the subject [38]. In our day, it is considered that overconsumption during pregnancy might cause various harms [39].

The studies suggesting that coffee roasting methods can also support various problems state that it also has a preventive effect against inflammatory situations for its antioxidant nature [40]. Apart from its leading to consumption disorders, the amount of consumption is also considered important. Whether coffee consumption has positive effects on or triggers certain diseases is still being discussed and it seems that it will remain as an unesolved issue for the science world for a long time. On the other hand, it can be easily observed in its regular web announcements that the American Food and Drug Administration (FDA) has a pretty clear understanding on the matter. Although not considered as a dangerous situation as opioid or alcohol, when regular coffee con- 
sumption is quitted at once, it might cause withdrawal, therefore it is recommended to quit it gradually. Another important warning is that the amount of excessive consumption changes according to the individual [41, 42].

\section{Conclusion}

The market shares of caffeine-based foods and beverages, which are among the most popular substances legally offered to people of all ages, are continuously increasing. It might spring to mind that one of the reasons for this may be that the ads published on TV and social media are promotive and especially oriented to children. On the other hand, overconsumption of caffeinated substances that can cause disorders yet are accepted by both the International Health Organization and the American Psychiatric Association, should not be linked solely to ads. Monitoring and limiting the consumption at a certain level especially for minors can help them benefit from possible positive effects of coffee while protecting from its harms and thus avoid a problematic outcome. When we consider that individuals who completed their adolescent development can self-control, they are expected to consider that avoiding overconsumption is an important measure for their health so as to avoid any disorder.

\section{References}

1. Ögel K (2020a). Bağımlılık Asla Sadece Bağımlılık Değildir, İletişim: Ankara.

2. Weinberg BA \& Bealer BK (2001). "The World of Caffeine: The Science and Culture of the World's Popular Drug” Londra: Routledge, Taylor \& Francis Group 2001.

3. Wise RA \& Robble MA (2020). Dopamine and Addiction. Annual Review of Psychology 71: 79-106.

4. Yildirim A, Şimşek H (2008). Sosyal Bilimlerde Nitel Araştırma Yöntemleri, (6. Baskı). Seçkin Yayıncılık, Ankara 2008.

5. Olekalns N \& Bardsley P (1996). Rational addiction to caffeine: An analysis of coffee consumption. Journal of Political Economy 1996: 104.

6. Rajaseharan D, Jeffin-Shanu JE \& Thulasiraman S (2021). Caffeine dependence among medical interns of a TertiaryTeaching Hospital. International Journal of Community Medicine and Public Health 8: 593-596.

7. APA (2013). American Psychiatric Association, Diagnostic and Statistical Manual of Mental Disorders, Fifth Edition, American Psychiatric Publishing

8. Jain S, Srivastava AS \& Verma RP (2017). Caffeine addiction, need for awareness and research and regulatory measures. Asian Journal of Psychiatry 41: 73-75.

9. Heinz A, Daedelow LS, Wackerhagen C \& Di Chiara G (2019). Addiction theory matters-why there is no dependence on caffeine or antidepressant medication. Addiction Biology 25: 25 .

10. Ögel K (2020b). Bağımlılık ve Tedavisi Temel Kitabı, 3. Bask1, 2020, IQ Kültür Sanat: İstanbul.

11. Macit MS (2020). Kahve tüketiminin obezite tedavisinde destekleyici rolü, Geleneksel ve Tamamlayıcı Tıp Dergisi 3:
119-127.

12. Nichols H (2017). "What does Caffeine do to your Body", Medical News Today. Erişim Adresi: https://www.medicalnewstoday.com/articles/285194

13. Freedman ND, Park Y, Abnet CC, Hollenbeck AR \& Sinha $R$ (2012). Association of cofee drinking with total and cause-specificmortality. The New England Journal of Medicine 366: 1891-1904.

14. Hughes JR, Oliveto AH, Helzer JE, Higgins ST \& Bickel WK (1992). Should caffeine abuse, dependence, or withdrawal be added to DSM-IV and ICD-10? The American Journal of Psychiatry 149: 33-40.

15. Bolton S \& Null G (1981). Caffeine Psychological Effects, Use and Abuse. Orthomolecular Psychiatry 10: 202-211.

16. Temple J (2009). Caffeine use in children: What we know, what we have left to learn, and why we should worry. Neuroscience\&Biobehavioral Reviews 33: 793-806.

17. Budney AJ \& Emond JA (2014). Caffeine Addiction? Caffeine for Youth? Time to Act! Society for the Study of Addiction 109: 1771-1772.

18. Zulli A, Smith RM, Kubatka P, Novak J, Uehara Y, et al. (2016). Caffeine and cardiovascular diseases. Critical review of Current Research, Eur J Nutr 55: 1331-1343.

19. Bhojaraja VS, Janardhan H, Hameed NA, Gulsoom FAR \& Ali MZ (2016). Knowledge, attitude and practices towards consumption of caffeine containing drinks among the student population of Ras-Al Khaimah Medical and Health Sciences University. UAE, International Journal of Research in Medical Sceiences 4: 3537-3541.

20. Budney AJ, Lee DC \& Juliano LM (2015). Evaluating the validity of caffeine use disorder. Curr Psychiatry Rep 17: 74.

21. Foxx RM \& Rubinoff A (1979). Behavioral threatment of caffeinism: Reducing excessive coffee drinking. Journal of Applied Behavior Analyses 12: 335-344.

22. Evatt DP, Juliano LM \& Griffiths RR (2016). A brief manualized treatment for problematic caffeine use: A randomized control trial. Consult Clin Psychology 84: 113-121.

23. Budney AJ, Brown PC, Griffifths RR, Hughes JR \& Juliano LM (2013). Caffeine withdrawal and dependence: A convenience survey among addiction professionals. Journal of Caffeine Research 3: 67-71.

24. Richards G \& Smith AP (2016). A review of energy drinks and mental health, with a focus on stress, anxiety, and depression. Journal of Caffeine Research 6: 49-63.

25. Samaha A, Tassi AA, Yahfoufi N, Gebbawi M, Rached M, et al. (2020). Data on the relationship between caffeine addiction and stress among lebanese medical students in Lebanon. Data in Brief 28: 104845.

26. Favrod-Coune T \& Broers B (2021). Addiction to caffeine and other xanthines. In: el-Guebaly N, Carrà G, Galanter M, Baldacchino AM (eds) Textbook of Addiction Treatment. Springer, Cham 2021: 215-228.

27. Temple JL, Bernard C, Lipshultz SE, Czachor JD, Westphal JA \& Mestre MA (2017). The safety of ingested caffeine: 
A comprehensive review. Frontiers in Psychiatry 8: doi: 10.3389/fpsyt.2017.00080.

28. Bidel S, Hu G \& Tuomilehto J (2007). Coffe consumption and type 2 diabetes- an extensive review. Central European Journal of Medicine 3: 9-19.

29. Zhang H, Lee ZX \& Qiu A (2020). Caffeine intake and cognitive functions in Children. Psychopharmacology 237: 31093116.

30. Kristjansson AL, Kogan SM, James JE \& Sigfusdottir D (2021). Adolescent caffeine consumption and agressive behaviour: A longtidunal assessment. Substance Abuse 42: 450453.

31. Cooper RK, Lawson SC, Tonkin SS, Ziegler AM, Temple JL, et al. (2020). Caffeine enhances sustained attention among adolescents. Experimental and Clinical Psychopharmacology. Advance online publication 29: 82-89.

32. Repantis D, Bovy D, Ohla K, Kühn S \& Dresler M (2021). Cognitive enhancement effects of stimulants: A randomized controlled trial testing methylphenidate, Modafinil and Caffeine. Psychopharmacology 238: 441-451.

33. Chandio ZA, Sidiqua A, Khaskheli MI, Waghani A \& Metlo WA (2020). Review Effect of Caffeine Overdose, RADS J Biol Res Appl Sci 11: 140-144.

34. Treur JL, Taylor AE, Ware JJ, Nivard MG, Neale MC, et al. (2016). Smoking and caffeine consumption: A genetic analyses of their association. Addiction Biology 22: 1090-1102.
35. DeVido JJ (2020). Stimulants: Caffeine, Cocaine, Amphetapine, and Other Stimulants. Absolute Addiction Psychiatry Review, (içinde) Marienfeld C. (eds) Absolute Addiction Psychiatry Review. Springer, Cham 2020: 185-203.

36. Hashibe M, Galeone C, Buys SS, Gren L, Boffetta P, et al. (2015). Coffee, tea, caffeine intake, and the risk of cancer in the PLCO cohort. British Journal of Cancer 113: 809-816.

37. Nieber K (2017). The impact of coffee on health. PlantaMed 83: 1256-1263.

38. Poole R, Kennedy O, Roderick P, Fallowfield JA, Hayes PC, et al. (2017). CoffeConsumption and health: umbrealla review of meta-analysesof multiple health outcomes, the BMJ 359: $1-18$.

39. Cornelis MC (2019). The impact of caffeine and coffee on human health. Nutrients MDP 11: 416.

40. Saltan FZ \& Kaya H (2018). Kahve: Bir farmakognozik derleme, FABAD J. Pharm. Sci 43: 279-289.

41. U.S. Food \& Drug Administration (2018). "Spilling the Beans: How Much Caffeine is too much?" Erișim Adresi: https://www.fda.gov/consumers/consumer-updates/spillingbeans-how-much-caffeine-too-much

42. K Xu, D G Di Luca, M Orrú, Xu Y, Chen JF, et al. (2016). Neuroprotection by Caffeine in the MPTP Model of Parkinson's Disease and its Dependence on Adenosine A2A Receptors. Neuroscience 322: 129-137.
Copyright: (C2022 Patrizia Muradi. This is an open-access article distributed under the terms of the Creative Commons Attribution License, which permits unrestricted use, distribution, and reproduction in any medium, provided the original author and source are credited. 